\title{
MILTON SANTOS E A PAISAGEM: PARÂMETROS PARA A CONSTRUÇÃO DE UMA CRÍTICA DA PAISAGEM CONTEMPORÂNEA ${ }^{1}$
}

\author{
MILTON SANTOS AND THE LANDSCAPE: PARAMETERS FOR TO CONSTRUCT ONE \\ CRITICISM OF CONTEMPORANEOUS LANDSCAPE
}

\author{
Angelo Serpa \\ Professor adjunto, doutor do Departamento de Geografia da Universidade Federal da Bahia, pesquisador \\ do CNPq. \\ e-mail:angserpa@ufba.br
}

\begin{abstract}
RESUMO
Busca-se resgatar as principais idéias contidas no texto da conferência proferida pelo professor Milton Santos no II Encontro Nacional de Ensino de Paisagismo em Escolas de Arquitetura e Urbanismo do Brasil, realizado na Faculdade de Arquitetura e Urbanismo da Universidade de São Paulo em 1995. Essas idéias serviram de ponto de partida para a formulação de duas questões norteadoras do presente artigo: Como construir uma crítica da paisagem contemporânea? Como o ensino e a pesquisa de paisagismo podem contribuir para a construção dos parâmetros dessa crítica? A hipótese principal é a de não haver possibilidade de construção de uma crítica da paisagem contemporânea, sem uma crítica consistente do espaço e do todo estrutural. Conclui-se que uma crítica da paisagem construída sob as premissas apresentadas aponta para a construção de parâmetros que revelem, por meio dos arranjos socioespaciais, o invisível das formas urbanas visíveis, tratando os objetos técnicos de modo sistemático e globalizante. É necessário revelar, por trás dos sistemas de objetos, os sistemas de valores que embasam as ações dos diferentes agentes e grupos que produzem espaço.
\end{abstract}

Palavras-chave: Milton Santos, paisagem contemporânea, crítica da paisagem construída, espaço urbano, sistema de objetos e sistema de ações.

\begin{abstract}
The article tries to rescue the main ideas of teacher Milton Santos text of his conference in the II National Meeting of Landscape Planning Teaching into Brazilian Architecture and Urbanism Schools, that happened in São Paulo University Architecture and Urbanism School, on 1995. These ideas are the starting-point to the two questions that direct the article: how to do a criticism of contemporaneous landscape? How can teaching and search in Landscape planning contribute to construct the parameters for this criticism? The main hypothesis is that there is no possibility to construct one criticism of contemporaneous landscape without a dense criticism of the space and the whole structure. The article conclude that one landscape criticism constructed on the presented premises points to parameters construction that may show the invisible of visible urban patterns, though social-spatial arrangements and considering the technical objects in a globalize and systematic way. It is necessary to revel the value systems that base the actions of different agents and groups that produce spaces and that is behind the object systems.
\end{abstract}

Key words: Milton Santos, contemporaneous landscape, criticism of builder landscape, urban space, objects systems and action systems. 
Remetemo-nos aqui, primeiramente, à conferência proferida pelo professor Milton Santos no II Encontro Nacional de Ensino de Paisagismo em Escolas de Arquitetura e Urbanismo do Brasil, realizado nessa mesma Faculdade de Arquitetura e Urbanismo há 11 anos. Acreditamos importante resgatar algumas daquelas idéias, pois elas, hoje, parecem ter ainda mais sentido e atualidade do que quando elaboradas na forma da conferência citada e porque temos, também, a sensação de faltar, em nossos últimos encontros, discussões epistemológicas mais aprofundadas sobre o conceito de paisagem e sua operacionalização no ensino e na pesquisa de paisagismo no Brasil.

Eis as idéias que gostaríamos de sublinhar durante nossa intervenção, apresentadas neste primeiro momento, sem estabelecer uma hierarquia prévia entre elas:

- Tendência muito forte, originada da prática política dos arquitetos, urbanistas e paisagistas, em considerar, com freqüência, o objeto como ator;

- os riscos do formalismo, do empirismo e do funcionalismo;

- a possibilidade de tratamento dos objetos de forma sistemática e globalizante;

- os objetos têm qualidades de primeira ordem, naturais e técnicas, e qualidades de segunda ordem, qualidades "sociais";

- os objetos e a paisagem não têm valor, o valor é dado pelo espaço, pelo casamento entre o sistema de objetos e o sistema de ações;

- a paisagem é sistema material; o espaço, sistema de valores;

- a paisagem é sempre fragmentária, uma "totalidade morta", a paisagem é o agido, não a ação, a paisagem é uma categoria técnica;

- o paisagista é o especialista suscetível, com o urbanista, de oferecer um projeto de quadro material de vida;

- o papel dos arquitetos, paisagistas e urbanistas é relativo, porque o valor dos objetos depende das formas de organização social;

- a paisagem é, sobretudo, produzida por não-paisagistas, a partir de "pedacinhos", construções isoladas;

- é a análise da paisagem produzida, o nosso mais importante trabalho: não é só propor novas paisagens, mas criticar as paisagens, tal como elas são.

Consideramos especialmente instigante esse último ponto, que podemos desdobrar nas seguintes questões:

- Como construir uma crítica da paisagem contemporânea?

- Como o ensino e a pesquisa de paisagismo podem contribuir para a construção dos parâmetros dessa crítica?

Pode-se construir essa crítica a partir da paisagem como artefato e como sistema, já que a paisagem é, evidentemente, uma produção humana, caracterizando-se como um conjunto de elementos/objetos interligados. Pode-se também elaborar uma crítica da paisagem contemporânea a partir da idéia de paisagem como riqueza, visto existirem paisagens que podem melhor favorecer a produção de riquezas, como ideologia, pois a paisagem sempre exprime e condiciona um conjunto de crenças e idéias, transmitindo "ideologia (s)", e como história, já que a paisagem cristaliza momentos e períodos históricos em seus processos de constituição (e transformação): 
"A paisagem nada tem de fixo, de imóvel. Cada vez que a sociedade passa por um processo de mudança, a economia, as relações sociais e políticas também mudam, em ritmos e intensidades variados. A mesma coisa acontece em relação ao espaço e à paisagem que se transforma para se adaptar às novas necessidades da sociedade." (SANTOS, 1997, p. 37)

A paisagem resulta sempre de um processo de acumulação, mas é, ao mesmo tempo, contínua no espaço e no tempo, é una sem ser totalizante, é compósita, pois resulta sempre de uma mistura, um mosaico de tempos e objetos datados. A paisagem pressupõe, também, um conjunto de formas e funções em constante transformação, seus aspectos "visíveis", mas, por outro lado, as formas e as funções indicam a estrutura espacial, em princípio, "invisível", e resulta sempre do casamento da paisagem com a sociedade.

Não há possibilidade de construção de uma crítica da paisagem contemporânea, sem uma crítica consistente do espaço e do todo estrutural. É da unidade orgânica entre o sistema de objetos (sistema material) e o sistema de ações (sistema de valores) que pode surgir os parâmetros dessa crítica. A paisagem tem uma constituição técnica, é constituída de objetos técnicos que vão desempenhar papéis específicos na vida social. Mas esses papéis são relativos porque vão depender das formas de organização social.

"Ora, se nós sabemos, através da constituição técnica do objeto, aquilo que ele pode oferecer, nós estamos em muito melhor condição para sugerir aos especialistas da sociedade, o tipo de sociedade que deve ser instalada. Mas isso supõe que nós conheçamos claramente, que nós sejamos capazes de analisar claramente, a constituição dos objetos. E a capacidade funcional desses objetos. Como também a capacidade funcional dos arranjos, porque é isso que fazem os planejadores. Eles escolhem os objetos, eles escolhem os arranjos entre objetos... Esses arranjos não são apenas para produzir uma sensação de beleza; não têm uma vocação puramente estética, têm uma vocação pragmática." (SANTOS, 1996a, p. 40-41)

Se concordarmos com Milton Santos que os objetos possuem qualidades naturais e técnicas, mas também qualidades "sociais", os objetos (e a paisagem) não têm valor, e o valor é dado pelo espaço, então uma crítica da paisagem deve ser construída a partir do entendimento do espaço como estrutura e processo, relacionando o sistema de objetos a um sistema de valores ditados, em última instância, pelas relações sociais e políticas, mas também (e sobretudo!) pelo fluxo da história.

Analisar e construir uma crítica da paisagem contemporânea a partir da análise do espaço implica em olhar as paisagens como especificações de uma totalidade da qual fazem parte "através de uma articulação que é ao mesmo tempo funcional e espacial" ou, em outras palavras, realizações de "um processo geral, universal, em um quadro territorial menor, onde se combinam o geral (...) e o particular" (CORRÊA, 1986, p. 46).

O movimento que transforma a totalidade em "multiplicidade" também a individualiza por meio das formas. Os fragmentos dessa totalidade, ao se tornarem "objetivos", continuam integrando a totalidade, mas sempre estão em função da totalidade que permanece "íntegra": "Cada indivíduo é apenas um modo da totalidade, uma maneira 
de ser; ele reproduz o Todo e só tem existência real em relação ao Todo." (SANTOS, 1996b, p. 98)

Em seu movimento permanente, a sociedade está sempre subordinada à lei do espaço preexistente, o que faz do espaço um todo estrutural. O espaço é, de acordo com Santos (1994), "a totalidade verdadeira", porque dinâmica, resultado e condição dos processos de geografização da sociedade sobre o conjunto de paisagens que constituem uma configuração territorial (SANTOS, 1994; SERPA, 2006).

"A totalidade é, ao mesmo tempo, o real-abstrato e o real-concreto. Só se torna existência, só se realiza completamente, por meio das formas sociais, incluindo as geográficas. E a cada momento de sua evolução, a totalidade sofre uma nova metamorfose. Volta a ser real-abstrato." (SANTOS, 1996b, p. 98)

Uma crítica da paisagem deve ser construída a partir da elaboração de uma fenomenologia da paisagem. Uma fenomenologia assim deve olhar cada paisagem como real-concreto, como uma "aparição" única e particular de um real-abstrato infinito de possibilidades, cuja essência se revela em cada aparição como o "sentido" de uma série de aparições (SARTRE, 2005). Ou seja, uma crítica fenomenológica da paisagem deve revelar o invisível espacial presente no "visível" de cada paisagem, de cada aparição, enquanto "essência", construindo uma tipologia baseada em sistemas materiais e sistemas de valores.

No entanto, é necessário reconhecer, como já fizemos em outras ocasiões (SERPA, 2006), as limitações de uma leitura formal e funcional das paisagens para a construção da crítica desejada, já que nem sempre a realidade visível esclarece completamente o que, de fato, acontece no espaço. As paisagens podem "mentir" (CLAVAL, 2004), se não admitirmos que não é somente a "realidade objetiva" que deve reter nossa atenção, mas também como essa realidade fala aos sentidos do sujeito que observa (e critica). É preciso reconhecer, como Claval, a paisagem enquanto conivência, explorando seus "fios cruzados e trocas recíprocas" (CLAVAL, 2004, p. 49). Vista assim, a paisagem é, ao mesmo tempo, marca e matriz, já que, ao que parece, "as sociedades organizam seus ambientes em função da percepção que elas têm deles e, reciprocamente, parece que elas os percebem em função da organização que dão a eles" (BERQUE, 1999, apud CLAVAL, 2004, p. 50).

Tomemos um exemplo: partindo da observação do "real-concreto" de um sistema de espaços livres de edificação, em um bairro popular qualquer de uma metrópole brasileira, e considerando esse sistema como paisagem, portanto, como "aparição una e particular" de uma realidade total e estrutural, como enxergar, para além do visível, o invisível (ou real-abstrato) que irá fundamentar nossa crítica? Uma descrição fenomenológica de várias dessas aparições, baseada exclusivamente no que essas revelam, enquanto dados imanentes ou objectalidades (HUSSERL, 2000), poderia ser sintetizada - enquanto essência de uma série de aparições - da seguinte maneira:

- Formação e consolidação de centralidades intrabairros, que determinam uma hierarquia dos espaços livres de edificação existentes; 
- maior diversificação do comércio e dos serviços nas áreas consolidadas como centralidades, onde há também uma apropriação mais intensa e diversificada dos espaços livres de uso coletivo;

- urbanização espontânea crescente dos espaços livres de edificação de uso coletivo, que tendem a desaparecer nas áreas mais segregadas (menos centrais), especialmente locais não-consolidados como de uso público;

- carência de áreas livres e de lazer, com a concentração dos usuários nas poucas áreas consolidadas como praças e largos nos centros de bairro (SERPA, 2002).

Tal descrição inclui, iá para além de um sistema de objetos, também um sistema de ações, mesmo apenas "vislumbrado", permitindo a intuição de uma paisagem periférica enquanto essência, que traduz um padrão periférico de ocupação dos bairros populares nas metrópoles brasileiras (SERPA, 2002). Estaríamos a meio caminho de uma crítica da paisagem contemporânea, entendida aqui justamente como enunciado por Milton Santos e já mencionado no início dessa intervenção, como uma paisagem produzida por não-paisagistas, a partir de "pedacinhos", de construções isoladas.

Poderíamos ir além, instigados pelas idéias de Milton Santos, e perguntarmo-nos por que nos debruçamos tão pouco sobre essas "paisagens", por que não enxergamos nelas a possibilidade de construção de paisagens e espaços mais cidadãos, a cidadania vista aqui como real-abstrato, como a possibilidade de construção de diferentes paisagens e espaços pelos diferentes agentes e grupos. Paisagens e espaços que respeitem e não hierarquizem as diferenças e valorizem a autonomia e a liberdade como valores supremos e universais. Para isso, devemos abandonar a consideração, corrente entre os planejadores, dos objetos como "atores" e do "visível" das paisagens como um fim em si mesmo.

A questão da visibilidade das formas urbanas nos processos de requalificação da cidade contemporânea aponta para outro exemplo emblemático para o paisagismo urbano: os parques públicos. Uma análise fenomenológica das "aparições" desse tipo de equipamento mundo afora revela a essência ou a razão de série do fenômeno "parque": a concepção e implantação de novos parques públicos parecem estar sempre subordinadas a diretrizes políticas e ideológicas (SERPA, 2003). Na cidade contemporânea, o parque público é um meio de controle social, sobretudo das novas classes médias, destino final das políticas públicas, que, em última instância, procuram multiplicar o consumo e valorizar o solo urbano nos locais onde são aplicadas. No mundo ocidental, - lazer e o consumo das novas classes médias são os "motores" de complexas transformações urbanas, modificando áreas industriais, residenciais e comerciais decadentes, recuperando e "integrando" waterfronts, desenvolvendo novas atividades de comércio e de lazer "festivo" (SERPA, 2004).

A palavra de ordem é investir em espaços públicos "visíveis", sobretudo os espaços centrais e turísticos, graças às parcerias entre os poderes públicos e as empresas privadas. Esses projetos sugerem uma ligação clara entre "visibilidade" e espaço público. Eles comprovam também o gosto pelo gigantismo e pelo "grande espetáculo" em matéria de paisagismo, arquitetura e urbanismo. De forma deliberada, os novos parques pú- 
blicos se abrem mais para o "mundo urbano exterior" e inscrevem-se em um contexto geral de "visibilidade completa" e espetacular. Projetados e implantados por arquitetos e paisagistas ligados às diferentes instâncias do poder local - verdadeiras "grifes" do mercado imobiliário -, os novos parques se tornam também importante instrumento de valorização fundiária na cidade contemporânea (SERPA, 2003).

Analisando criticamente esse último exemplo, pode-se dizer que a paisagem produzida pelos paisagistas, arquitetos e urbanistas é também uma paisagem não-cidadã, já que os parques urbanos não podem ser considerados em sentido pleno e irrestrito como públicos. Se for certo que o adjetivo "público" diz respeito a uma acessibilidade generalizada e irrestrita, um espaço acessível a todos deve significar, por outro lado, algo mais do que o simples acesso físico a espaços "abertos" de uso coletivo. Pois a acessibilidade não é somente física, mas também simbólica, e a apropriação social dos espaços públicos urbanos tem implicações que ultrapassam o design físico dos "novos" parques. Muitos desses lugares permanecem "invisíveis" para a maioria da população, que não dispõe de "capital escolar" para se apropriar das linguagens projetuais e do repertório utilizados no desenho urbano contemporâneo. Pode-se mesmo afirmar que as clivagens sociais ganham aqui status de "segregação social" ou mesmo de exclusão. Tudo isso contribui para a "invisibilidade" desses equipamentos - em contradição com seu "princípio projetual de base", a visibilidade completa e espetacular -, tornando-os exclusivos para o uso de "iniciados". Existe, portanto, uma distância mais social que física, separando os novos parques urbanos daqueles com baixo capital escolar (SERPA, 2004).

$\mathrm{Na}$ cidade contemporânea, o parque público se transformou em "objeto de consumo", em expressão de modismos, vendidos pelas administrações locais e por seus parceiros empresários como o "coroamento" de estratégias (segregacionistas) de requalificação urbana (SERPA, 2005). A forma urbana é promovida, aqui, por imagens que satisfazem as comunidades profissionais de arquitetos e paisagistas, bem como os contratantes dos projetos. Esses profissionais são obrigados a fazer-se compreender por membros de um júri, seduzi-los por imagens de acesso fácil e imediato. Com a difusão quase instantânea, pelas revistas técnicas, dessas imagens, a arquitetura e o paisagismo se transformam em fenômenos da moda, com seus ciclos curtos de alguns anos e seus pequenos grupos de pressão profissional formando uma rede internacional (CHOAY, 1988).

Uma crítica da paisagem construída sob as premissas apresentadas no início dessa intervenção aponta, pois, para a construção de parâmetros que revelem, pelos arranjos socioespaciais, o invisível das formas urbanas visíveis, tratando os objetos técnicos de modo sistemático e globalizante. É necessário revelar, por trás dos sistemas de objetos, os sistemas de valores que embasam as ações dos diferentes agentes e grupos que produzem espaço. Trata-se de intervir no todo estrutural (o espaço), introduzindo novos objetos em arranjos urbano-regionais, cuja lógica deve ser compreendida, analisada e criticada, ao invés de relegada ao plano dos "desvios" ou do "indesejável".

$\mathrm{Se}$, nos bairros populares da cidade contemporânea, falta espaço para intervenções paisagísticas e urbanísticas "de monta", é necessário afinar o olhar para o sistema de 
ações que se operacionaliza sobre um sistema de objetos aparentemente inadequado para o lazer e as manifestações culturais e festivas de seus moradores. É necessário abandonar a perspectiva tradicional que, no fundo, desejaria o extermínio de paisagens classificadas a priori como "não-cidadãs" ou, sob essa mesma ótica, como paisagens sem "qualidade ambiental". É necessário se ocupar dos espaços ocultos e residuais, das "lajes" de uma paisagem que "espontaneamente" se verticaliza, dos interstícios das construções, dos "restos" de espaços dos becos e vielas, em que a população dos bairros populares compartilha seus encontros, seu lazer e sua diversão. Como intervir nessas paisagens a partir do real-concreto existente? Como intervir para construir um real-abstrato de cidadania, modificando o real-concreto das paisagens e dos espaços não-cidadãos?

Devemos, como Milton Santos, enfatizar que não há possibilidade de construção dessa cidadania desejada prescindindo de seu "componente territorial", já que "o valor do indivíduo depende do lugar onde ele está e que, desse modo, a igualdade dos cidadãos supõe, para todos, uma acessibilidade semelhante aos bens e serviços" (SANTOS, 1992, p. 113). Devemos, portanto, como pesquisadores e profissionais da paisagem e do espaço, debruçar-nos de forma crítica e ativa, sobre as novas possibilidades de arranjos territoriais, nas quais os lugares sirvam realmente de "pontos de apoio" para a construção de paisagens e espaços mais cidadãos.

\section{Notas}

(1) Trabalho apresentado na mesa-redonda "Milton Santos e a Paisagem", no VIII ENEPEA - Encontro Nacional de Ensino de Paisagismo em Escolas de Arquitetura e Urbanismo do Brasil.

\section{Bibliografia}

CHOAY, Françoise. Conclusion. In : MERLIN, Pierre (Org.). Morphologie urbaine et parcellaire. Saint-Denis: Presses Universitaires de Vincennes (PUV), 1988.

CLAVAL, Paul. A paisagem dos geógrafos. In: CORRÊA, Roberto Lobato; ROSENDAHI, Zeny (Orgs.). Paisagens, textos e identidade. Rio de Janeiro: EDUERJ, 2004.

CORRÊA, Roberto Lobato. Região e organização espacial. São Paulo: Ática, 1986.

HUSSERL, Edmund. A idéia da fenomenologia. Lisboa: Edições 70, 2000.

SANTOS, Milton. Pensando o espaço do homem. 4. ed. São Paulo: Hucitec, 1997.

. Da paisagem ao espaço: Uma discussão. In: II ENCONTRO NACIONAL DE ENSINO DE PAISAGISMO EM ESCOLAS DE ARQUITEURA E URBANISMO DO BRASIL, 2, 1995, São Paulo. Anais do II ENEPEA. São Paulo: Universidade São Marcos/FAUUSP, 1996a.

A natureza do espaço. São Paulo: Hucitec, 1996b.

Metamorfoses do espaço habitado. 3. ed. São Paulo: Editora Hucitec, 1994.

O espaço do cidadão. 2. ed. São Paulo: Nobel, 1992.

SARTRE, Jean-Paul. O ser e o nada. Ensaio de ontologia fenomenológica. Petrópolis: Vozes, 2005.

SERPA, Angelo. O trabalho de campo em geografia: uma abordagem teórico-metodológica. Boletim Paulista de Geografia, São Paulo, v. 84, p. 7-24, 2006. 
SERPA, Angelo. Parque público: Um "álibi verde" no Centro de Operações Recentes de Requalificação Urbana? Cidades. Presidente Prudente-SP, v. 2, n. 3, p. 111-141, 2005.

Espaço público e acessibilidade: Notas para uma abordagem geográfica. GEOUSP - Espaço e Tempo, São Paulo, v. 15, n. 15, p. 21-37, 2004.

. Parque público e valorização imobiliária nas cidades contemporâneas: Tendências recentes na França e no Brasil. In: ENCONTRO NACIONAL DA ANPUR: ENCRUZILHADAS DO PLANEJAMENTO - REPENSANDO TEORIAS E PRÁTICAS, 10, 2003, Belo Horizonte, Anais... Belo Horizonte: ANPUR/UFMG, 2003, CD-ROM.

. A paisagem periférica. In: YASIGI, Eduardo (Org.). Turismo e paisagem. São Paulo: Contexto, 2002. 